\title{
PERSONS WITH HEARING IMPAIRMENTS IN EUROPE-SOCIAL AND SCIENCE PERSPECTIVES
}

\author{
Jasmina Kovačevića ${ }^{\text {,*, }}$ \\ Zora Jačova ${ }^{\text {b }}$ \\ Husnija Hasanbegovićc \\ Vesna Žigića \\ Dragana Maćešić-Petrovića \\ Boris Kovačevićd
}

Original scientific paper

University of Belgrade, Faculty of Special Education and Rehabilitation, Serbia ${ }^{a}$

University "St. Cyril and Methodius", Faculty of Philosophy, Department of Special Education and Rehabilitation, Republic of Macedonia ${ }^{b}$

University of Tuzla, Faculty of Special Education and Rehabilitation ${ }^{c}$

Institute for Behavioral Disorders, Belgrade, Serbia

$\begin{array}{lc}\text { Received: } 08.02 .2016 & \text { UDC: } 376.1-056.263: 004 \\ \text { Accepted: } 28.02 .2016 & 376.1 .026\end{array}$

\begin{abstract}
Aim: The study deals with the effects of new system of rehabilitation by using individual dynamic programs through computer technology in the education and rehabilitation of persons with hearing impairments. The sample includes adolescents of both gender distribution with the hearing impairment, average intellectual abilities, between 15 and 18 years of calendar age, attending the secondary vocational training school $(N=49)$. Results: The results point to a significant statistical difference between the achievements of the examinees who underwent the classical educational rehabilitation treatment and those whose education was based on individual dynamic programs through computer technology, in favor of the latter. Conclusion: The study deals up with new social, cultural and science perspectives viewed throw the implementation of assistive technology in education and rehabilitation of deaf people.
\end{abstract}

Key words: assistive technology, hearing impairments, adolescents, innovative models, education and rehabilitation.

\section{INTRODUCTION}

The research point up the significance of the implementation of assistive technology in education and rehabilitation of the students with hearing impairments. The paper is based on the state that computer technologies are very important area of the modern rehabilitation and education processes of the per- sons with developmental disabilities. The new way of thinking and behaving in modern social, public and living conditions, reflects also on the teaching process at regular school as well as in special education, i.e. at schools specialized for the children with impaired hearing.

\footnotetext{
Correspodence to:

Jasmina Kovačević, University of Belgrade, Faculty of Special Education and Rehabilitation

Visokog Stevana 2, 11000 Belgrade, Serbia

E-mail: kovacjasmina@gmail.com
}

*FUNDING: Article is realized under the project "Creating a protocol to assess educational potential of children with disabilities, as a criterion for the development of individual educational programs", No. 179025, Ministry of Science and Technology, Belgrade, 2011-2016, project manager prof.dr Jasmina Kovačević 
There is a constant search for the newer, more efficient way of learning, based on the needs, preoccupation and goals of the young generations of students of all ages. Therefore the modern approaches in education are consisted of the system of new methods and procedures (developed in final two decades of 20th century), and also consisted of didactic systems which change the technology of teaching process which scope is to remove the contradictions between the aim of teaching on one side and organization of subject meter and the teaching process on the other. The emphasizing of the active forms of teaching puts the student into the position of active subject which learns and develops his knowledge, habits and skills, finds and summarizes the results of effort and learning, along with his teacher. That kind of teaching method represents the best action against the formalism and routine, and also the way of humanization of teaching.

Today, the school is expected to create adequate conditions for progress and stimulation of dynamic skills of students, considering that only well informed, competent, highly motivated and well guided individuals can answer to the different challenges of modern society. Those individuals also have to be ready for permanent changes. Therefore, the one of the aims of modern teaching for the children with impaired hearing is to motivate the students to be more independent in learning and working, to see objectively their own abilities, to take the responsibility for working actions, to learn how to behave in facing problems and challenges, to develop the communication and cooperative skills, to handle the organization skills, and also to learn how to resolve the conflict situations. Nevertheless, there is the question how to organize the lectures which will not provoke the stress and bother, and in one satisfy the needs of modern society. One of the schools' answers is to improve the teaching process with the innovative working models which will contribute the teaching and learning, as well as the assimilation of the knowledge, which will be usable in practice. Those things lead to the expected changes in the students' behavior (Kovacevic \& Macesic-Petrovic, 2012).

The aim of the education process is to realize the changes. If the forming of the teaching process is based on student's motivation for an adequate solving of the teaching tasks, it will open the way for realization of the primary education scope, and that is the independence in learning process, awaking of the creative skills, self-education, as well as the enabling for self-evaluation of his and other's achieved results. The different teaching models are elaborated in newer pedagogic and methodic literature, in which the accent is on the active participation of student in the learning process. Most of the recommended models are used in practical work and the teachers realize them with noticeable success, in their curriculum. The theoretic elaboration, as well as the using of innovative teaching models are mostly related to regular school However, that kind of the research is recently also very present in the field of special education, i.e. in education of students with hearing problem. The value of already used teaching models can be seen in the fact that almost every model is compatible with the traditional system and that the teacher in the course of organization and use of the chosen model may successfully use already gained teaching experience. Naturally, the applying of the certain model requires some changes in organization and realization of existing teaching program, but doesn't require the radical changes of teaching practice and violation of present work concept (Kovačević \& Maćešić-Petrović, 2010). Well balanced and moderated use of these innovative models along with the traditional ones leads to the reducing and removing of the main flaws of traditional teaching which is present as at special schools, where the children with and youth with impaired hearing are educated, as well as at the school for typical population, in which are educated the children without impairment.

New system of rehabilitation in this paper means the concept of implementation an assistive technology as a new model of rehabilitation and education in Europe such as new social challenges and new social science perspectives in this scientific area. Article in this field have explored new areas such as implementation of assistive technology and computers in education and rehabilitation processes, both of which address the complex of conditions that impact lives of this people and produce opportunity and privilege (Ampofo, BeokuBetts \& Osirim, 2008). The notion of assistive technology may mean a device or a service, namely any item, part of equipment or a product of a system that may be used to increase or improve functional capacities of an individual with developmental disabilities (Maćešić-Petrović, 2008). According to other bibliographical sources, assistive technology is a descriptive term which means using equipment in the treatment of children and adults with developmental disabilities with a view to compensating functional limitations, as well as improving learning abilities, mobility (movement), communication, choice and control within an environment (Cain \& Taber, 1990; Brody, 1999; Alm, 2001). 
Furthermore, the term means a direct service in assisting individuals to choose, master and apply such devices (Caccamise \& Lang, 1996; Cook \& Hussey, 2002; Chambers, 2003).

In 1991 Copel pointed to the importance of assistive technology in helping persons with disabilities to bridge barriers to their independence and inclusion. In that sense, assistive technology is a compensational mechanism in functional limitations in all aspects of life, ensuring greater freedom to persons with developmental disabilities in all spheres of their existence. Assisted by technology, the user may communicate with others, participate in recreational and social activities, in learning, working and employment, exercise control in the environment in which he/she lives, thus promoting and improving his/her abilities in everyday life and daily activities (www. people1.org/articles/asst_tech_about.htm).

Assistive technology may help persons with developmental disabilities in numerous segments of functioning and existence. Many sources of information in the field emphasize developmental and existential segments in which assistive technology plays an important role, including communication and education as the most significant ones. The use of assistive technology in the schools educating students with developmental disabilities, particularly those with hearing impairments, is of utmost importance. Very frequently the question arises as to whether the school should make assistive technology available to the students that need it. The Individuals with Disabilities Education Act (IDEA) points to the need to apply assistive technologies in the case of all children for whom individual educational programs are drawn up. Computer programmed learning packages open up new possibilities for a more dynamic instruction; visualization of teaching contents enhances memory, and students may do extra work at home (Kovacević \& Maćešić-Petrović, 2010; Žigić \& Radić-Šestić, 2006). Particularly devised computer programs enable each student to master different contents in accordance with their psychophysical abilities and at their own pace. In designing computer programs for students with hearing impairments it is important to transform all audio information into a visual form in the most suitable fashion, taking into account the consequences of the impairment; it is equally important to make all visual signs noticeable even if the user is not looking at the screen, and to make it possible for the user to switch the sound on and off depending on his/her needs. In such a manner children are enabled to receive information with minimum difficulties.

Numerous studies confirm the positive impact of communication and information technologies on the development of linguistic, reading, writing and calculation skills, as well as on the general intellectual and social development of students with hearing impairments (Caccamise \& Lang, 1996). The use of computers enables the application of a large number of methods within a short time span, since the application of one method always leads to searching for another one, which in turn results in modernized instruction, improved learning process and the transfer of the acquired knowledge (Lewis,1993). The use of computers in educating students with hearing impairments is justified by the fact that the rehabilitation and partly the education of children with hearing impairments are implemented individually through specific sessions, in which advantages of the computer as a medium are unlimited, particularly when it comes to problem instruction, but also in the case of other innovative models of educating persons with hearing impairments.

In this manner it is possible to adjust educational contents to each student, putting the emphasis on the issues that he/she finds more familiar and interesting, thus ensuring better diagnosing of difficulties in the learning process, as well as the ways of their overcoming. Although there is disagreement among researchers regarding the advantages of the computer in educational achievements, they all agree on one point: the use of the computer reduces the time needed for learning, ensures direct feedback as a strong motivational factor, and boosts self-confidence and independence in work.

Naturally, there are still many outstanding issues, including the quality of computer software, the level of competence of the team, particularly the special educator, for participating in its design and application, as well as the selection of teaching contents which can be computerized. The selection of educational contents is essential, especially in the case of the contents requiring computer stimulation through analytical-synthetic approach. Proceeding from such a theoretical approach, a practical research framework was defined in order to examine the efficiency of application of individual work programs through computer technology in the educational rehabilitation treatment of adolescents with hearing impairments. 


\section{The problem of the research}

While we were developing the innovative teaching model in education of the children with impaired ${ }^{2}$ hearing, we supposed that the use of the innovative teaching would effect on achievement of better school results of children, and that would also affect on improving of positive motivation in school subjects, learning, and school in general. That is why the problem of our research was to experimentally determine the effectiveness of using the computer teaching, in which dominates the individual learning and the group form of working, and to compare it with the traditional education in which mostly dominates the frontal way of teaching, considering the adopted knowledge of students with impaired hearing.

\section{METHOD}

The sample includes adolescents with the hearing impairment, between 15 and 18 years of calendar age, with average intellectual abilities and without any additional impairments, attending the secondary vocational training school. The sample is consist of experimental $(\mathrm{N}=26)$ and control group $(\mathrm{N}=23)$.

The sample includes adolescents from a one school in order to exclude the impact of factors such as individual differences of students belonging to different groups, working conditions in schools, availability of computers for individual student work, teachers' competence for creating and applying innovative work models, particularly through computer technologies. There are five special education schools in Serbia, offering education and vocational training to children with the hearing impairment.

Considering the school achievement, i.e. the mark they got at the beginning of the school year in the subjects tested in the sample, there were 8 pupils with the satisfactory mark $(16,32 \%), 11$ pupils with the good mark $(22,44 \%), 15$ pupils with the very good mark $(30,61 \%)$ and 15 pupils with the excellent mark $(30,61 \%)$. Considering the gender distribution the sample included $27(55,10 \%)$ male examinees and $23(44,89 \%)$ female examinees.

${ }^{2}$ The level of hear impairment is determined by the classification of The World Health Organization: up to $40 \mathrm{~dB}$ - mild hearing impairment; from $41 \mathrm{~dB}$ to $60 \mathrm{~dB}$ - moderate hearing impairment; from $61 \mathrm{~dB}$ to $80 \mathrm{~dB}$ severe hearing impairment; over $80 \mathrm{~dB}$ profound hearing impairment
Considering the hearing impairment the sample included $8(16,32 \%)$ examinees with the moderate hearing damage, $12(24,48 \%)$ examinees with the severe damage and $29(59,18 \%)$ examinees with the profound hearing impairment.

The school has different workshops for practical instruction. It also has modern computers and technical aids; there is a computer room where computers are available for each student for individual work. In that room numerous experiments were conducted examining the application of innovative models within the teaching procedure. The teachers are especially trained to apply innovative work methods and techniques, particularly computer technologies in the educational rehabilitation of students with hearing impairments.

The study relied on the procedure of using specially designed and adapted individual educational rehabilitation programs applied through computer technology. The programs were differentiated according to the scope and complexity of the contents for each student, so that they were adjusted to the students' cognitive abilities, as well as their ability to follow and understand verbal and written instructions, depending on the level of their development. The program package consisted of two parts. The first part was a study material containing a written text whose basic parts were illustrated and presented throw various pictures; with the possibility to constantly repeat the actions and their textual presentation. The second part was a material for repeating and testing the acquired knowledge. It comprised questions and answers classified according to complexity, from the easier to the more difficult ones. The student could move on to the next question if he/she answered correctly. Should the answer be incorrect, the student would be returned to the previous stage to relearn the unachieved contents. We followed the effects of applying this program contents by establishing the difference between the achievements shown on the criterion-referenced test of the knowledge acquired through applying standard verbal and non-verbal teaching methods and techniques and the achievements shown on the test of the knowledge acquired based on individual work programs through computer technology. The study went on throughout a school year and the results were evaluated upon a three month period.

The criterion-referenced knowledge test was harmonized with the acquired educational contents and it was especially elaborated for that occasion by a team consisting of a special educator, a pedagogue and a psychologist. 
The test contained 16 tasks from the covered educational fields defined in the school curriculum. The total number of points was 46 . The results were classified according to a point scale in the following manner: unsatisfactory - up to 19 points, partly satisfactory - from 20 to 26 points, good - from 27 to 33 points, fairly good - from 34 to 40 points and very good - from 41 to 46 points. The grades were in accordance with the regular school grades officially used to evaluate student's scholastic ability: 1- failing grade, 2- passing grade, 3- good, 4- very good, 5- excellent.

A computer statistical analysis program was used for particular techniques for calculating the frequency and percentage of the examinees' answers, as well as the $\chi 2$ test, in order to establish differences in the results of the classical educational rehabilitation treat- ment on the one hand, and the computer technology treatment, on the other.

The study controlled all variables that might be relevant for the achievement of the studied sample, such as:

- The level of education (school grade)

- Gender distribution (sex rate)

- Socio-economical level

- Chronological distribution (calendar age)

- Presence/absence of bilingualism

- Implementation of other rehabilitation procedure.

In this segment is a part of a more comprehensive research innovative, so that due to the pertinent limitations in space and content, it will not be presented in relation to the features of the sample and overall results of this study.

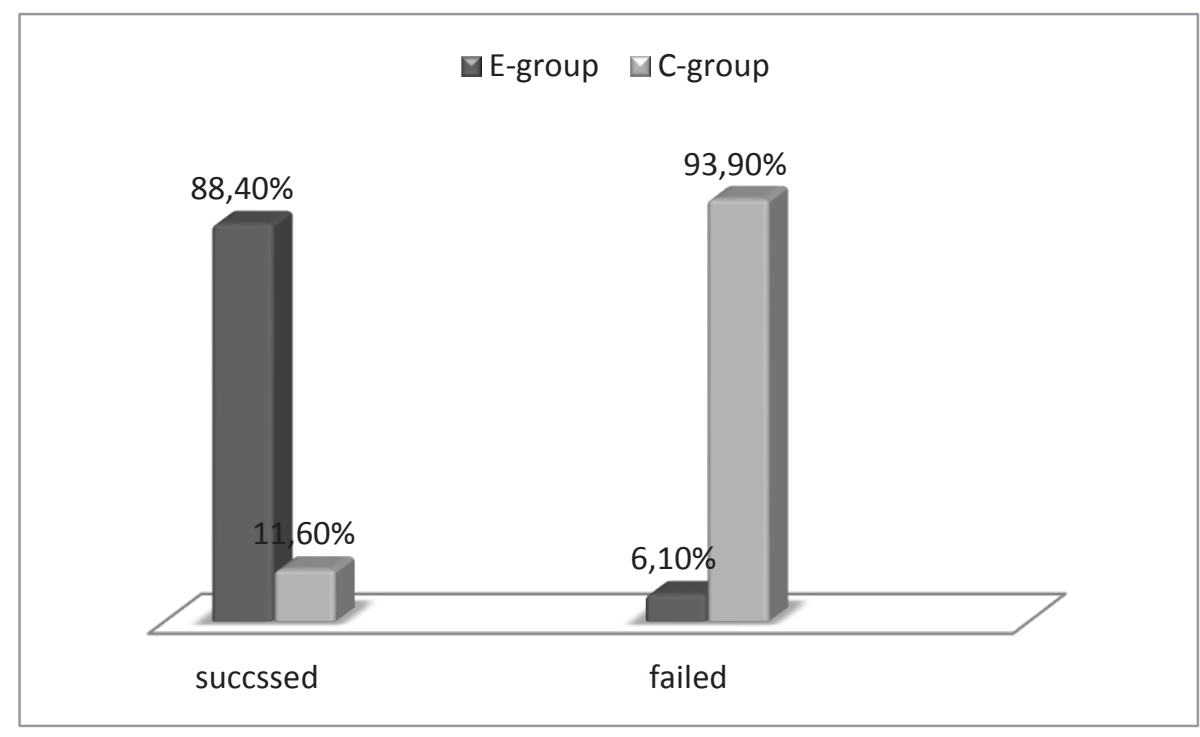

Graph 1 Test results upon the classical educational treatment and upon the application of individual programs through computer technology

The results achieved on the knowledge test upon the classical educational rehabilitation treatment and those achieved upon the application of individual work programs through computer technology, point out the higher success of the students included in individual programs lessons through computer technology (Chart 1). The results indicate that the students included in the experimental group mostly received grade excellent and very good $(88.40 \%)$. In control group there was a less excellent and very good students (see Graph 1).

Table 1 Results of the statistical analysis

The differences in achievement between the implemented programs and groups

\begin{tabular}{llll}
\hline$\chi^{2}=10.40$ & $\mathrm{dF}=3$ & $\mathrm{p}<0.01$ & $\Phi=0.46$
\end{tabular}


Statistical analysis of the results obtained between experimental and control group point out the statistical significant differences in achievement on the implemented programs $\left(\chi^{2}=10.40 ; \mathrm{dF}=3 ; \mathrm{p}<0.01\right.$;
$\Phi=0.46$. That means that children who are educated by the computer technique programs are much better in school achievement and acquiring knowledge and vice-versa.

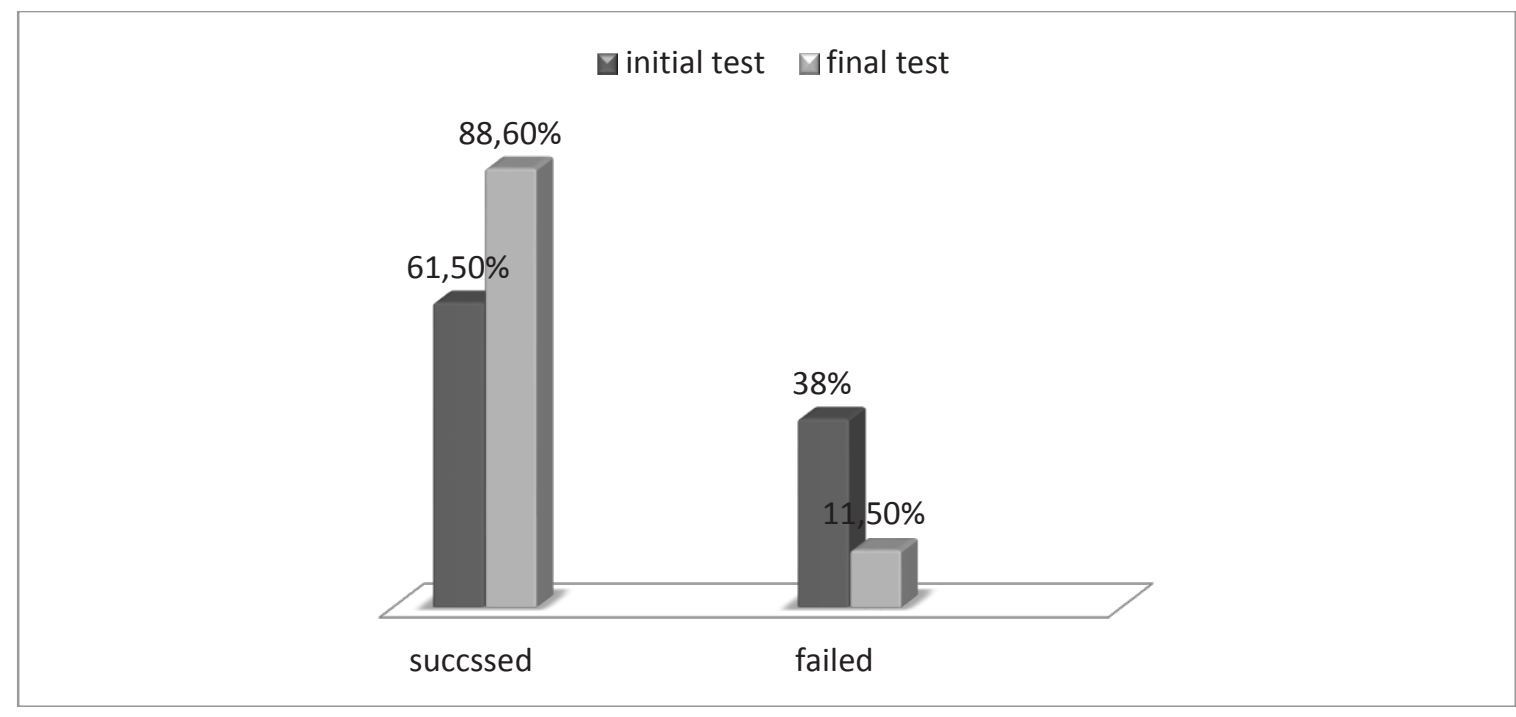

Graph 2 Test results of the implementation of the computer technology in experimental group

Table 2 Results of the statistical analyses

The differences between initial and final tests of knowledge in E group

\begin{tabular}{llll}
\hline$\chi^{2}=20.19$ & $\mathrm{dF}=9$ & $\mathrm{p}<0.001$ & $\Phi=0.64$
\end{tabular}

The results of the implemented computer technique in experimental group point up the high statistical significance between initial and final tests of knowledge $(\chi 2=20.19 ; \mathrm{dF}=9 ; \mathrm{p}<0.001 ; \Phi=0.64)$.
That means that students from experimental group show much better achievement in tested conceptual area and acquiring knowledge after implementation the contents of the school subjects by the computer technique.

Table 3 Rank of the analyzed didactic values of the innovative teaching

\begin{tabular}{cll}
\hline Rank & Didactic value & $\mathbf{\%}$ \\
\hline 1. & More interesting and more engaging teaching mode & 100 \\
\hline 2. & Motivation enhancement & 85.72 \\
\hline 3. & Encouraging the individual expanding of knowledge & 85.72 \\
\hline 4. & Developing different interests & 85.72 \\
\hline 5. & Balancing the speed and rhythm of work & 72.85 \\
\hline 6. & Encouraging independence in work & 72.85 \\
\hline 7. & Greater responsibility for the results & 72.85 \\
\hline 8. & Developing sense for work dividing & 57.28 \\
\hline 9. & Building the need for cooperation & 57.28 \\
\hline
\end{tabular}


After realized research we have tested attitudes of the pupils in the area of the implementation of the new models of teaching work.

The pupils were presented with 10 didactic values in the form of adequate questions adapted to their age and experience in order to determine their attitudes towards the new teaching model. Analyzed values are shown in table 8 according to the pupils' evaluation.

\section{DISCUSSION}

The results achieved on the knowledge test upon the classical educational rehabilitation treatment and those achieved upon the application of individual work programs through computer technology, point to higher scholastic ability of the students included in individual programs through computer technology (Graph 1).

The results of the basic analysis achieved on the knowledge test between the classical educational treatment and the application of individual work programs through computer technology, point to higher scholastic ability of the students included in individual programs through computer technology (Graph 1). The results indicate that the students included in the experimental group mostly received grade excellent $(61.53 \%)$ and very good $(26.92 \%)$. In control group there was a less excellent and very good students (see Graph 1).

Furthermore, the designed program package enabled each student to independently control the mastering of the given educational contents, as well as the constant repetition of different parts of the contents or the contents as a whole, always in a dynamic fashion (Macesic-Petrovic, 2008). The advantages of computer programs are also reflected in the possibility for each student to return at any point to the contents which gave him foreknowledge for acquiring new knowledge, thus enabling easier transfer of the acquired knowledge through two-way communication (Caccamise \& Lang, 1996; Cook \& Hussey, 2002; Chambers, 2003). The knowledge acquired through computer technology was applied more quickly, easily and efficiently in practical work and in new, unfamiliar tasks and situations (Kovačević \& Maćešić-Petrović, 2010).

Therefore, the results of the conducted study are in accordance with the results of the majority of authors who indicate that the application of computers in the educational process is conducive to higher efficiency in learning at higher cognitive levels, as computer programs encourage students to find the correct answer by discovering facts, thus stimulating their cognitive development (Cain \& Taber, 1990; Brody, 2000; Alm,
2001). For adolescents with hearing impairments the presentation of educational contents through computers, pictures, charts, and above all animation, is interesting and, at the same time, suitable in view of the secondary consequences and limitations which depend on the degree of hearing impairment.

We also must mentioned that this is civil war population which has been educated and treated throw the period of civil war in former Yugoslavia which affected their achievement by factors such as globalization, immigration and natural disasters. Because of this the article explores those critical areas of research frequently addressed to the Europe which have last year's been ignored or marginalized in our environmental context such as family, work, social and political movements (Ampofo, Beoku-Betts \& Osirim, 2008).

The results in table 1 show that the pupils evaluated the didactic values positively, i.e. above $50 \%$ in average. These values, in fact, stress the educational significance of the computer teaching. So far, the dominant way of teaching at regular schools, but also at schools specialized for the children with impaired hearing has implied that the pupils most of the time follow lectures with the aim of remembering as precisely as possible the presented facts. Consequently, pupils' main activities are memorizing and, if the need arises, literal reproduction of the memorized facts that have no real value because they neither encourage students, nor can they be used in real-life situations.

The individually models of teaching, such as computer teaching, as one of the teaching models, offers a scheme which gives greater freedom to pupils when it comes to the activities regarding planning, organizing and realization of teaching (Meyer, 2001). Pupils are no longer passive recipients but active participants in teaching which significantly and qualitatively changes their attitudes towards school and learning. The individually teaching puts a stress on individual needs and abilities of pupils without neglecting the importance of shared and individual responsibility in teaching especially for the final outcome.

Therefore, improving of quality of education applying the innovative learning models and techniques, is the one of the main aims of the present special education reform. In this manuscript we point up the part of the research which confirms the assumption that the hearing impairment does not have to be an obstacle for quality and long-lasting adoption of knowledge if the teaching process is adjusted to cognitive and linguistic abilities of children with impaired hearing and if the chosen techniques and methods are in accordance with their individual possibilities and abilities. 
Analyzing the existing processes of education of children with impaired hearing in The Republic of Serbia it is determined that the school work is mostly directed to the speaking and linguistic skills development, that the significant time is spent on a vocal pronunciation and assimilation of partial concepts. It is also determined that the new learning techniques and assimilation of knowledge from social environment does not get an adequate attention. Therefore, improving of quality of education applying the innovative learning models and techniques, is the one of the main aims of the present special education reform. In this manuscript we will show the part of the research which confirms the assumption that the hearing impairment does not have to be an obstacle for quality and long-lasting adoption of knowledge if the teaching process is adjusted to cognitive and linguistic abilities of children with impaired hearing and if the chosen techniques and methods are in accordance with their individual possibilities and abilities.

The modernization of teaching process and methods of interactive learning, is also motivated by the research results which showed a higher efficiency in knowledge assimilation and a positive influence on quality of assimilated knowledge, and especially an influence on duration of adopted knowledge and on its applying in everyday situations (Kovačević \& Maćešić-Petrović, 2010).

Therefore, improving of quality of education applying the innovative learning models and techniques, is the one of the main aims of the present special education reform. In this manuscript we will show the part of the research which confirms the assumption that the hearing impairment does not have to be an obstacle for quality and long-lasting adoption of knowledge if the teaching process is adjusted to cognitive and linguistic abilities of children with impaired hearing and if the chosen techniques and methods are in accordance with their individual possibilities and abilities.

The traditional teaching is mainly limited by the teaching plan and program which have to be realized throughout the clearly defined teaching units, thematic units and lessons. The adopted knowledge, skills and abilities are often inadequately related with subjects, i.e. the relative relation doesn't exist.

The accent is mostly on the realization of the material and partly functional teaching tasks. The knowledge is passed in the structural form, often in a deductive way. The techniques of finding the solutions to problems are being practiced and the boundaries of strait program are rarely crossed. The tasks are usually of a closed type with one solution and settled solving methodology, and the problem type of tasks, which would motivate the students to independent research and independent search for appropriate methodical solutions, are missing. There is no connection with the practical needs and experience. The traditional teaching styles are prevailing, especially the frontal way of teaching, which is based on the methods of teaching and discussing. The individual work is rarely practiced, as well as the teamwork, wherewith the educative part of teaching is ignored. Unlike the traditional teaching, the modern teaching is oriented to student, it creates the partnership between the teacher and student, it is ready to deal with the problem situations and tasks, it is correlated to different scientific areas and human activity, it develops the cooperation in team work and contributes to the development of the organizing and communication abilities of students.

The main advantages of the innovative teaching are:

- all teaching participants are included in realization of general aim, so that every student, in accordance with his abilities and possibilities, contributes to the realization of the set learning goal,

- the students' activities are higher, and the liberty in the communication between the group members is more visible. The students remind each other of the forgotten themes and with collective activity come to the results,

- the relations student-student, and student-teacher are better

- the use of the innovative teaching contributes to the students' socialization, because with that kind of work organization they adopt social skills, develop communication and tolerance, and in one deal with different kinds of prejudices,

- the most important advantage of the innovative teaching is the cooperative, collective team work in which the students' self-confidence and self-respect is fortified,

- there are no classical knowledge checking tests, which affects the students' studying and learning motivation,

- the adopted knowledge and methods are long lasting, and the acquired skills and habits can be used in everyday life.

The nominated faults of traditional teaching and the advantages of the innovative one, indicate the need for innovation of teaching process, because the different working models are the components that characterize the good teaching. 
But, if the teaching process is consisted of one, although innovative, teaching model, the lessons become boring as well as the in the frontal teaching. Although based on such a limited sample, the results are in accordance with those of most other authors, indicating that the application of computer technology as an assistive means in the educational process and its combination with the classical educational procedure, methods and forms of work, promotes student's scholastic ability and affects the quality of the acquired knowledge (Lewis, 1993; www.people1. org/articles/asst tech about.htm; Žigić \& RadićŠestić, 2006; Maćešić- Petrović, 2008; Kovačević, \& Maćešić-Petrović, 2010).

\section{CONCLUSION}

The results of this study points out the significance of the teaching model tested in the research. That is the teaching model which successfully integrates the interdisciplinary educational work and correlation of content with the multimedia package in team work, group interaction, in practical learning and experimental work which is less demanding for students. In the modern education systems the innovative teaching is becoming one of the important forms of learning and teaching, while the realization of students' innovative, in the developed education systems, takes $30 \%$ of the annual lessons. The significant education scopes are achieved using the innovative work. The students learn how to explore the chosen theme independently, in fellows work and mutual cooperation, than learn how to make the important decisions in order to accomplish required goals and withal motivate one another to be more involved. That kind of teaching changes the role of teacher as well as of the student in whole teaching process. For the teacher this working model means the additional involvement and certain courage which could be the interesting motivation for students, but it can also be followed with some difficulties. The teacher's courage mostly has a motivational character and it can be seen in the fact that he/she is ready to deviate from the boundaries of teaching program, ready to reorganize the teaching time, to apply the different work forms and methods, while the difficulties are the uncertain innovative result, and possible unexpected situation and problem. The essence of the innovative work consists of guiding the students' interests, developing self-organization and personal responsibility, than, consists of detailed planning phase by phase, interdisciplinary, developing different learning models and methods, self-organized learning and autonomy in choosing the themes and contents.

Therefore the goals of the innovative teaching are divided into the goals that concern the students and the general goals of innovative teaching.

The goals of innovative teaching that concern the students are directed to:

- developing the ability for team work and cooperative learning,

- developing the ability of taking decisions, individually and in the group,

- developing of the critical attitude towards one's own and the other's work,

- developing of the organization and communication abilities

- recognizing the importance and sense of work sharing

The general innovative teaching goals are:

- developing of individual learning and responsibility

- developing of the ability of planning,

- enabling for using of a different teaching means and methods

- encouraging of autonomy in finding information and critical attitude towards them,

- enabling for the integration of all gained results,

- recognizing of teaching process and work in a social group,

- joining of the teaching subjects by interdisciplinary approach in solving problems,

- creating of product for your own and other's use

\section{REFERENCES}

Alm, N. (2001). Future Possibilities for Technology in the Workplace. London: Scotland Department of Mathematics and Computer Science.

Ampofo, A. A., Beoku-Betts, J. \& Osirim, M. (Eds.) (2008) Researching African Women and Gender Studies. New Social Science Perspectives. Special Issue African and Asian Studies 7(4): 323 - 563.

Brody, H. (1999). The great equalizer: PCs empower the disabled. PC/Computing, July 83-93.

Cain, E \& Taber, F. (1990). Educating people for the 21st century. Boston: Little, Brown Co.

Caccamise, F. \& Lang, H. (1996). Signs for science and mathematics: A resource book for teachers and students, Rochester. NY: National Technical Institute for the Deaf.

Chambers, A. (2003). Has technology been considered? A guide for IER teams. Reston: VA: CASE/TAM.

Cook, A. \& Hussey, S. (2002). Assistive technology: Principles and practices (2nd ed.). St. Louis, MO: Mosby. 
Kovačević, J. \& Maćešić-Petrović, D. (2010). Assistive Technology and Adolescents with Hearing Impairments. IV International Computer and Instructional Technologies Symposium Proceedings. Konya. pp.717720. ISBN: 978-605-61434-2-7

Kovacevic, J., Macesic-Petrovic, D. (2012). Inclusive education-Empirical experience from Serbia, International Journal of Educational Development, 32 (3) pp. 463-470

Lewis, R. (1993): Special education technology: Classroom applications, Pacific Grove, CA: Brooks/Cole.

Meyer, H. (2001). Turklinkendidaktik: Aufsatze zur Didaktik, Methodik und Schulentwicklung. Berlin: Cornelsen Verlag Scriptor.
Maćešić-Petrović D. (2008). Primena računara u edukaciji i rehabilitaciji kod dece sa intelektualnom ometenošću. Beograd: Univerzitet u Beogradu, Fakultet za specijalnu edukaciju i rehabilitaciju. www.people1. org/articles/asst_tech_about.html - Assistive Technology for People with Mental Retardation

Žigić, V. \& Radić-Šestić M. (2006). Računarska tehnologija za osobe oštećenog vida i oštećenog sluha. Univerzitet u Beogradu, Fakultet za specijalnu edukaciju i rehabilitaciju: Beograd. 